Research Article

\title{
The Adhesion of CrN Thin Films Deposited on Modified 42CrMo4 Steel
}

\author{
O. Lupicka and B. Warcholinski \\ Faculty of Technology and Education, Koszalin University of Technology, Sniadeckich 2, 75-453 Koszalin, Poland \\ Correspondence should be addressed to B. Warcholinski; bogdan.warcholinski@tu.koszalin.pl
}

Received 29 August 2017; Accepted 22 October 2017; Published 24 December 2017

Academic Editor: Hiroshi Noguchi

Copyright (c) 2017 O. Lupicka and B. Warcholinski. This is an open access article distributed under the Creative Commons Attribution License, which permits unrestricted use, distribution, and reproduction in any medium, provided the original work is properly cited.

\begin{abstract}
Here, the effect of adhesion of $\mathrm{CrN}$ hard coatings on modified $42 \mathrm{CrMo} 4$ steel substrate is presented. Modifications of the substrate are shot peening, nitriding, shot peening, and nitriding joined process. In the shot peening process, two variable process parameters were used: exposure time $(t)$ and air pressure $(p)$. The nitriding process was conducted in the following parameters: nitriding potential $N_{p}=4.86$, nitriding time $t_{n}=3 \mathrm{~h}$, and temperature process $T=530^{\circ} \mathrm{C}$. Modified substrates were characterized by surface hardness HV5 and hardness profiles on the cross section of samples and by surface roughness parameters. On such prepared substrates, the $\mathrm{CrN}$ coating was deposited. The adhesion of $\mathrm{CrN}$ coating on modified substrates was defined by the scratch test. Chemical and phase composition of the films was determined using EDS method and X-ray diffraction, respectively. The surface hardness of deposited films was also defined. The substrate of $42 \mathrm{CrMo} 4$ steel without mechanical and heat treatment coated by hard $\mathrm{CrN}$ film was used as a reference.
\end{abstract}

\section{Introduction}

Adhesion and hardness of thin coatings are the most important quantities that determine the various applications. Qualitative assessment of both of these parameters allows understanding the properties of the coatings, as well as their contribution to the development of others. Among numerous techniques used to evaluate the adhesion of the coating to the substrate, the scratch method is the most commonly used which allows to get quantitative image of adhesion. Critical load is defined as the force at which the coating is removed from the substrate, and it depends on many factors, including the hardness of the coating and the substrate, film thickness, roughness of the coating and the substrate, and the type of the substrate material $[1,2]$. On the one hand, it depends on the deposition technology of thin coatings and, on the other hand, on scratch test parameters (diamond indenter radius, the intenders travelling speed, and load increase rate). Some of these factors also affect the results of another test-qualitative assessment of the durability of the coating, the Daimler-Benz test. Both of these methods are complementary and provide a deeper assessment of the phenomena affecting the adhesion of the coating.

Among the plastic treatments modifying the surface layer, the shot peening plays an important role. During the process of shot peening on the treated surface dynamically, peening elements work in the form of balls (steel, glass, and ceramic). This method is used only as a strain hardening treatment. It is irreplaceable for machining limp and/or thin-walled objects, where the use of large static forces is impossible due to the deformation of the shape of the workpiece. Furthermore, after machining, the layer shows an increase in defects in the structure-dislocations, texture, shape, and size of the grains [3]. Shot peening is a method to improve the resistance of metal pieces to fatigue by creating regions of residual stress.

The results of thermochemical treatments are the layers formed by diffusion introducing a foreign element, which forms compounds (nitrides, borides, etc.) with very varied properties. Gas nitriding, one of the most common surface treatments used, consists in introduction of a nitrogen atom 
into the surface layer of the steel object usually thermally enhanced. The source of atomic nitrogen is ammonia, which dissociates at a temperature of nitriding on atomic hydrogen and nitrogen. The most important feature of the nitrided layers, especially on alloy steels, is their high hardness. The maximum hardness is achieved at low-temperature nitriding $\left(500-520^{\circ} \mathrm{C}\right)$, since at these temperatures, finely nitrides of alloying elements are formed.

The nitriding at elevated temperatures, in which nitrides of larger dimensions and lower coherence with the substrate are formed, leads to a reduction in hardness. Another advantage of nitriding is the possibility of protecting the surface against corrosion; to this purpose, so-called anticorrosive nitriding is used. In order to meet the above requirements, it is necessary to select the parameters of the nitriding process which enable the formation of a nonporous surface carbonitrides zone with a thickness of several micrometers protecting steel against corrosion. Nitrided layer also has a sufficiently high resistance to fatigue [3-5], abrasion [3], and cavitation erosion.

Each of the analyzed surface treatments is widely used in various industries (automotive, machinery, and aerospace). For several years, attempts have been made to their sequential use, in particular to the connection of nitriding and PVD processes or shot peening and nitriding. Nitriding of steel and PVD coating deposition have been the subject of many publications [6-9] as shot peening and PVD coating deposition $[10,11]$. To ensure good adhesion of coatings to the substrate nitrided, the formation of so-called "white layer" of iron nitrides $\varepsilon-\mathrm{Fe}_{2-3} \mathrm{~N}$ i $\gamma^{\prime}-\mathrm{Fe}_{4} \mathrm{~N}$ [12] on the surface should be reduced or completely eliminated. The improvement of the performance of tools and machine parts was obtained after the deposition of hard thin coatings on them, which significantly alter their properties. Chekour et al. [6] emphasized that the nitriding has a significant effect on the increase in durability. Tools with only $\mathrm{CrN}$ coating show 1.3 times higher durability compared with the uncoated tools. Nitrided substrates with $\mathrm{CrN}$ coating increase the tool's durability fourfold.

Chromium nitride has a relatively low coefficient of friction, good wear resistance, and high corrosion resistance. Due to the excellent resistance to abrasion, chromium nitride coating has been used as the coating on tools for cutting, milling, and threading of components made of titanium and its alloys, brass, copper, and other nonferrous metals, covering molds, stamps, and machine parts. Chromium nitride is characterized by high chemical resistance and has a very low affinity for nonferrous workpieces. These coatings can be prepared by various PVD including arc and magnetron techniques [13].

One of the critical parameters in the selection of the type of coating on the tool is the adhesion of the coating to the substrate. The hardness of the coating affecting the wear resistance, fracture toughness [7], structure, or the coefficient of friction will have little significance when the adhesion of the coating to the substrate is insufficient. Low adhesion results in an almost immediate flaking off of the coating on contact of the tool with the workpiece. It is the adhesion that characterizes the ability of the coating-substrate system to load transfer.
The energy of chemical bonds, the processes at the substratecoating interface such as mutual diffusion of atoms, and the substrate surface development are responsible for the adhesion. Reducing the surface roughness promotes the growth of adhesion [14].

Liu et al. [10] found that the hard coating or surface hardening increases wear resistance. It should be remembered that the brittle surface layer accelerates the initiation of cracks and reduces the fatigue life. In this case, it is helpful; for example, shot peening treatment increases considerably the material fatigue resistance.

One of the most important trends in surface engineering includes activities aimed at improving the mechanical properties of the coating-substrate systems. Additive synergistic effect can be achieved by combining existing surface treatments, such as mechanical with thermochemical or searching for new solutions. In particular, the objective of this study was to find an answer to the question of whether favorable changes in the properties of the substrate material resulting from the combined process of burnishing (shot peening) and gas nitriding are achieved.

In the present work, the adhesion of $\mathrm{CrN}$ thin coatings deposited on the substrate, previously modified by cold working (shot peening) or thermochemical treatment (gas nitriding) and by the combined process of shot peening and nitriding, was tested. As a reference, the ground substrate was used.

\section{Experimental}

The tests were conducted on samples made of $42 \mathrm{CrMo} 4$ structural steel with the following chemical composition (wt.\%): C (0.22), Si (0.35), Mn (0.70), P (0.01), S (0.001), Cr (1.12), Mo (0.26), and Fe balanced. All samples were hardened and tempered. The hardening was carried out for $8 \mathrm{~min}$ at a temperature of $845^{\circ} \mathrm{C}$ and tempering at a temperature of $620^{\circ} \mathrm{C}$ for $120 \mathrm{~min}$. After that, the hardness of the samples increased from $93 \mathrm{HRB}$ (19 HRC) to $30 \pm 1$ HRC.

2.1. Surface Modification. Quenched and tempered samples were subjected to shot peening, nitriding, and combined shot peening and nitriding process.

In the shot peening process, the shot marked as SW 170 of a diameter of $0.43 \mathrm{~mm}$ and a hardness of $470 \mathrm{HV}$ was used. The head of a diameter of $5.3 \mathrm{~mm}$, positioned $200 \mathrm{~mm}$ from the shot-peened substrate, was also used. Shot peening was performed at $120 \mathrm{~s}, 360 \mathrm{~s}$, or $600 \mathrm{~s}$, under the air pressure of $0.45 \mathrm{MPa}$.

The nitriding was conducted in a laboratory furnace with a vertical quartz retort of a diameter of $50 \mathrm{~mm}$ using the following process parameters: temperature $T=530^{\circ} \mathrm{C}$, nitriding time $t_{n}=3 \mathrm{~h}$, nitrogen potential $N_{p}=4.86$, and nitriding atmosphere $70 \% \mathrm{NH}_{3}+30 \% \mathrm{H}_{2}$. After the nitriding process, the samples were cooled down in the furnace.

$\mathrm{CrN}$ coatings were deposited using cathodic arc evaporation on the $42 \mathrm{CrMo} 4$ steel substrate. The substrate surface was previously modified by shot peening or nitriding or by the combined process of shot peening and nitriding. 
Before PVD process, the substrates were cleaned in an ultrasonic alkaline bath and then placed on the turntable in the working chamber at a distance of $18 \mathrm{~cm}$ from the arc source. The vacuum chamber vas evacuated to the base pressure of $1 \times 10^{-3} \mathrm{~Pa}$. The substrates were heated up to a temperature of $300^{\circ} \mathrm{C}$. Before the deposition of the coating, the substrates were cleaned by ion etching of metal ions at a voltage of $600 \mathrm{~V}$ for 10 minutes, and the argon pressure in the chamber was maintained at $0.5 \mathrm{~Pa}$ to remove weakly bonded particles on the surface. The improvement in the coating adhesion to the substrate was obtained by deposition of the thin chromium layer with a thickness of about $0.1 \mu \mathrm{m}$ directly on the substrate. The coating deposition was carried out with a substrate bias voltage bias of $-150 \mathrm{~V}$, arc current of $80 \mathrm{~A}$, and the nitrogen pressure of 1.8 Pa. Rotation speed of the table was $2 \mathrm{~min}^{-1}$.

2.2. Sample Characterization. The chemical composition of the CrN coating was determined using EDX (Oxford Link ISIS 300). The X-ray diffraction (XRD) with a glancing angle $\left(\omega=3^{\circ}\right)$ and Bragg-Brentano geometry was recorded on an $\mathrm{X}^{\prime}$ Pert PANalytical device using $\mathrm{Cu}-\mathrm{Ka}$ radiation in the range of 2 theta angles between 30 and $120^{\circ}$. The grain size was calculated using Scherrer's formula [15]. Due to instrumental peak broadening, $0.2^{\circ}$ for silicon standard, the Warren-Biscoe correction method was used [15].

The phase composition of the nitrided layer was determined by X-ray phase analysis. One aim of this analysis was to determine the volume fraction of the $\mu$ and $\gamma^{\prime}$ phases in the layer. For this purpose [16], the adjusted intensities of the main diffraction lines of the phases and iron $(\{101\}-\varepsilon$, $\{200\}-\gamma^{\prime}$, and $\left.\{110\}-\alpha-F e\right)$ were used. Layer thickness was calculated from the formula resulting from the absorption of Beer's law:

$$
g=\frac{\ln \left(I_{0} / I_{\alpha}\right) \sin \theta}{2 \mu},
$$

where $I_{0}$ is the diffraction line for initial state sample, $I_{\alpha}$ the diffraction line for nitrided sample, $\mu$ the linear absorption coefficient for the nitride layer, and $\theta$ the Bragg angle.

The studies of the sample structure on the cross sections were conducted on a Neophot 2 optical microscope, and the morphology studies on a Jeol JSM 5500LV scanning electron microscope were conducted. For the surface quality evaluation, the Nikon Eclipse Imaging MK200 optical microscope, equipped with Imaging Software NIS-Elements software, was applied. The data were automatically collected for quantitative and dimensional analyses of the macroparticles. All images were taken at the same magnification $(400 \mathrm{x})$, the same contrast, sharpness, and threshold of sensitivity. The measurements were taken for each sample at five points, located on a line at an equal distance from each other.

Hardness measurements on cross sections of the samples were determined by the Vickers method under the load of $0.1 \mathrm{kgf}(0.98 \mathrm{~N})$. For measuring the surface hardness, the loads of $0.5 \mathrm{kgf}(4.903 \mathrm{~N})$ and $5 \mathrm{kgf}(49.03 \mathrm{~N})$ were applied. The measurement was performed 15 times for each load, at different locations on the surface of each sample. The hardness of $\mathrm{CrN}$ coatings was determined using a FISCHERSCOPE ${ }^{\circledR}$ HM2000 nanoindenter with the indenter penetration depth of about $0.2 \mu \mathrm{m}$. The results were averaged based on 10 measurements.

The coating stresses were determined using Stoney's formula [17]:

$$
\sigma=\frac{E}{1-v} \cdot \frac{t_{s}^{2}}{6 t_{f}}\left(\frac{1}{R}-\frac{1}{R_{s}}\right),
$$

where $E$ is the Young modulus of the substrate, $v$ the Poisson coefficient of the substrate, $t_{f}$ the thickness of a layer, $R$ the radius of the substrate curvature together with the coating, and $R_{s}$ the radius of the substrate curvature. The curvature radius was calculated from the data obtained from the surface roughness analyzer (Hommel Werke Profilometer T8000). For this test, a silicon substrate of $0.3 \mathrm{~mm}$ thick, $30 \mathrm{~mm}$ long, and $4 \mathrm{~mm}$ width covered by $\mathrm{CrN}$ coatings was applied.

Surface roughness measurements were performed using a Hommel Tester T8000 profilometer.

The adhesion of the coatings was determined using the scratch test (CSEM Revetest ${ }^{\circledR}$ Scratch-Tester) with a Rockwell type $\mathrm{C}$ diamond indenter. It was moved at a speed of $10 \mathrm{~mm} / \mathrm{min}$ by linearly changing the load from 0 to $100 \mathrm{~N}$ at $100 \mathrm{~N} / \mathrm{min}$. Critical load $\mathrm{Lc}_{1}$ was defined as the force at which the first damage of the coating was observed, and $\mathrm{Lc}_{2}$ was determined as the load at which the total detachment of the coating from the substrate was observed. This load was determined by observing using an optical microscope with an average of at least three measurements. To check the adhesion of the coatings, the Daimler-Benz test [4] was also used. It depends on the assessment of the coating damage caused by the Rockwell intender pressed with constant load (ca. $1470 \mathrm{~N}=150 \mathrm{kgf}$ ) in the substrate-coating system. Depending on the type and quantity of the coating damage, it is assigned to one HF1 to HF6 groups, where HF1 to HF4 show good adhesion to the substrate and the marks HF5 to HF6 show poor adhesion.

\section{The Test Results}

3.1. Properties of the Surface Layer after the Shot Peening Process. As a result of the shot peening process, surface layers were obtained, whose properties were characterized, among others, through the study of surface roughness, surface hardness, and the hardness distribution on the cross sections of the samples.

In Figures 1 and 2, obtained by SEM, the characteristic change in the geometry of the surface after shot peening process can be seen. From the analysis presented in pictures, it ensures that the increase in the value of the exposure time $t$ increases the number of traces in the form of pits on the surface of the workpiece (Figure 1). It is shown explicitly in Figure 2, which presents the results of the roughness measurements.

The value of surface roughness parameter, $R_{a}$, of the samples before the shot peening had been $0.29 \mu \mathrm{m}$, and for the samples after shot peening, the value was in the range from 5.24 to $5.91 \mu \mathrm{m}$. The presented data show that the 


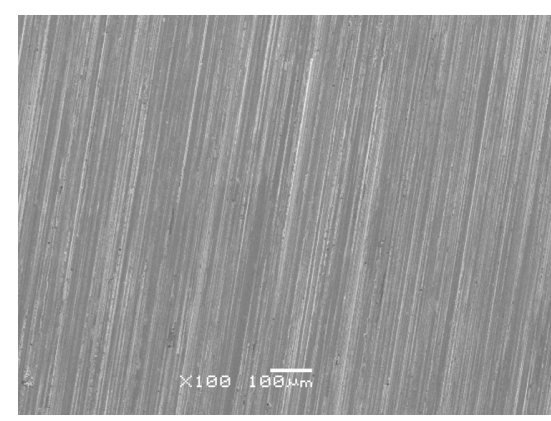

(a)

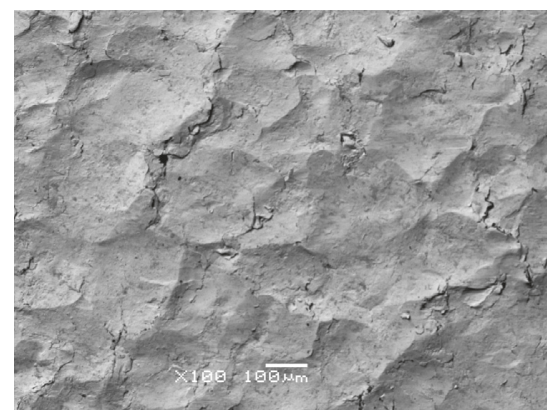

(c)

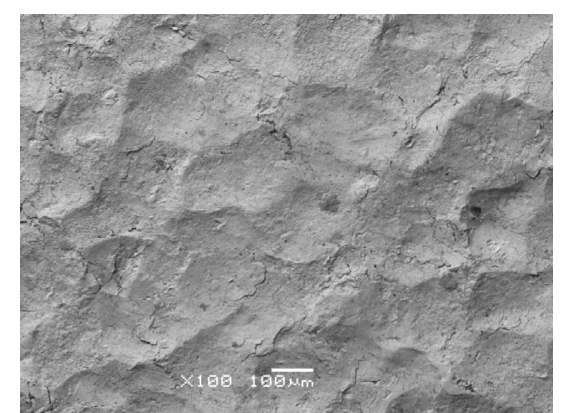

(b)

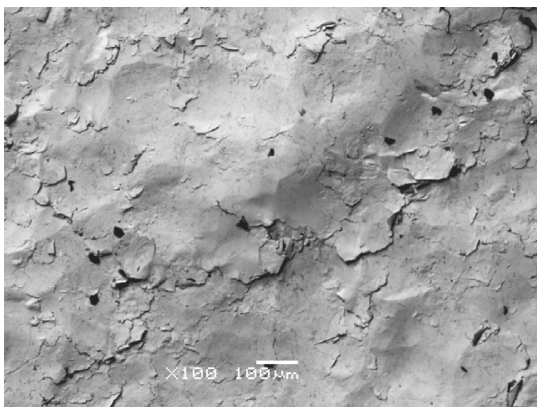

(d)

FIgUre 1: Metallographic photos taken on SEM: (a) initial substrates; (b) shot-peened substrate $(t=120 \mathrm{~s}, p=0.45 \mathrm{MPa})$; (c) shot-peened substrate $(t=360 \mathrm{~s}, p=0.45 \mathrm{MPa})$; (d) shot-peened substrate $(t=600 \mathrm{~s}, p=0.45 \mathrm{MPa})$.

surface roughness parameter, $R_{a}$, increased by about 20 times after the shot peening process, as compared to the surface roughness in the initial state. The lowest value of the parameter $\left(R_{a}=5.24 \mu \mathrm{m}\right)$ was obtained in the case of shot peening surface with the shortest exposure time of $120 \mathrm{~s}$, while the highest $R_{a}=5.91 \mu \mathrm{m}$ was obtained for the longest exposure time $600 \mathrm{~s}$. It follows that, with increasing exposure time, the surface roughness of shot-peened steel increases. In the same shot peening process, parameter ratio of roughness $R_{t}$ and $R_{z}$ is 17 times. Because of the roughness of the surface, hindering the performance of subsequent testing adhesion of $\mathrm{CrN}$, all samples were polished to $R_{a}$ about $0.029 \mu \mathrm{m}$.

The degree of deformation of the layer obtained by shot peening is different from that of the material in the initial state. The analysis of metallographic pictures shows that, as in the case of changes in surface roughness (Figure 2), there is an increase of crumple zones (Figure 3) with the increase of exposure time.

As a result of shot peening, the structure was obtained (Figure 3) with visible irregular deformations of layers, which has resulted from the repeated hitting of balls on the surface of the material being processed. The peening process also caused essential, from the strength properties point of view, microstructural changes in the surface layer (Figure 3). As a result of the applied heat treatment of steel (Section 2.1), a sorbitic structure was obtained. For burnished steels with sorbitic structure the formation of fine-grained amorphous surface layer containing separated high-dispersive carbides is characteristic. This layer is difficult to etch. Both the thickness of this layer and the amount of the carbide present

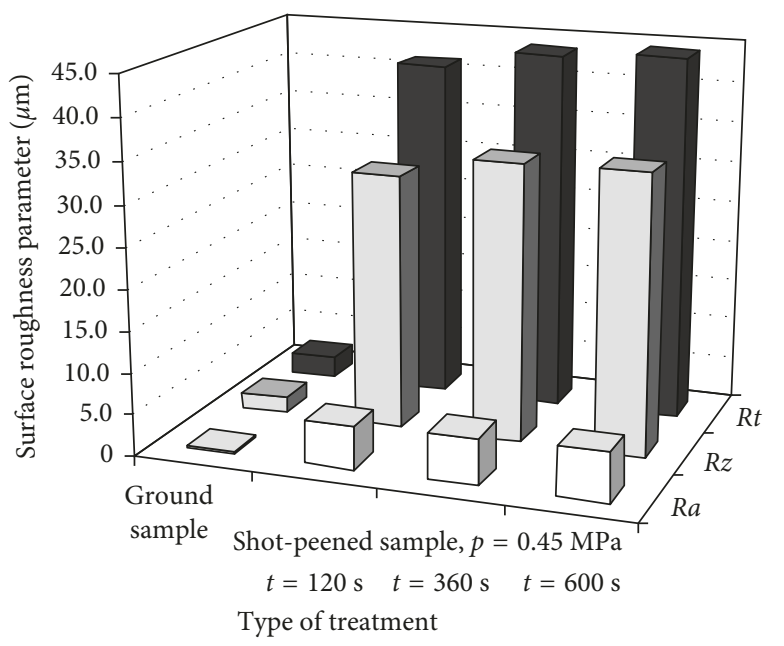

FIgURE 2: The parameters of surface roughness after grinding process (initial state) and after shot peening process.

in it are dependent on the degree of deformation and increase with the increase of degree of deformation [18].

In surface layer on account of its characteristic structure zone, smaller or larger differences (gradients) of virtually all elastic and plastic properties occur, represented by the increase of hardness. The surface hardness was measured on all samples subjected to shot peening process with the parameters set in Section 2.1. Comparing the results of changes of surface hardness (Figure 4) and structural changes (Figure 3), it can be concluded that the shot peening process causing larger changes 


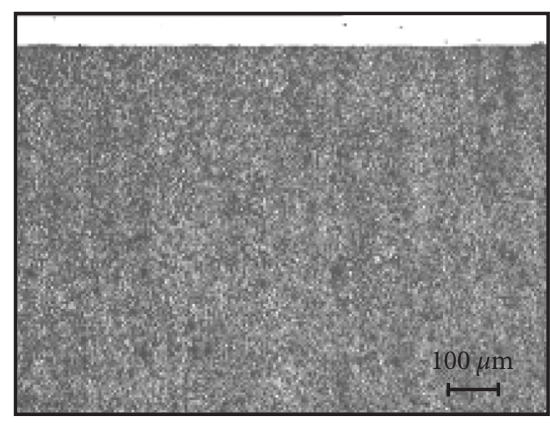

(a)

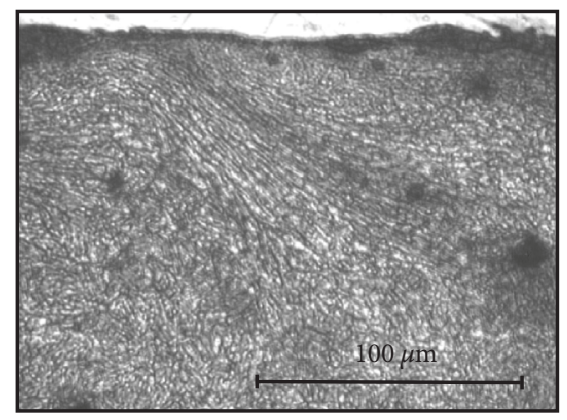

(b)

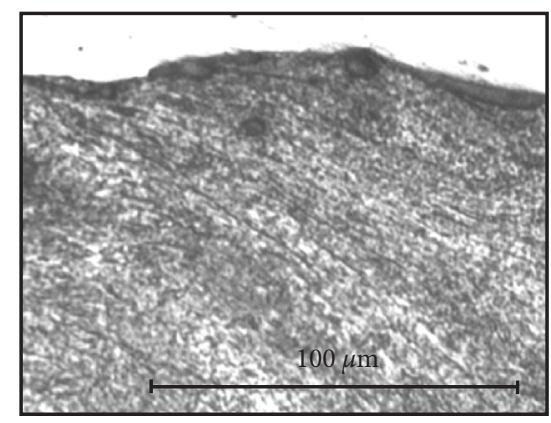

(c)

Figure 3: Photos taken on a cross section of an optical microscope: (a) sample ground, larger 50.4x; (b) shot-peened sample (the process parameters: $t=120 \mathrm{~s}, p=0.45 \mathrm{MPa}$ ); (c) shot-peened sample (the process parameters: $t=600 \mathrm{~s}, p=0.45 \mathrm{MPa}$ ).

in the structure of the surface layer results in simultaneous larger increase of surface hardness (Figure 4). Moreover, the analysis of the obtained results indicated that the process parameters for assumed maximum increment of surface hardness amounted to $216 \mathrm{HV} 5$, representing an increase of $72 \%$ relative to the hardness of the samples in the initial state. The surface hardness of the shot-peened sample in time $120 \mathrm{~s}$ amounted to 427 HV5 (relative to hardness of the sample in the initial state 299 HV5), extra time for shot peening causes an increase of hardness to 515 HV5.

The essence of the shot peening is a direct impact of peening elements on the treated surface. The surface layer is therefore characterized by high hardness, diminishing with the distance from the surface (Figure 5). To determine the hardness of the shot-peened zone, additionally, the measurements of hardness at a load of $0.5 \mathrm{~kg}(4.9 \mathrm{~N})$ were taken (Figure 4). In this case, the analogous character of changes in hardness was obtained, compared with the larger load $(5 \mathrm{~kg})$. The determined values are higher by about $150 \mathrm{HV} 0.5$. It should be noted that the depth of penetration of the indenter into the surface hardened zone was about $8 \mu \mathrm{m}$. The higher load, where depth of penetration was around $20 \mu \mathrm{m}$, includes a zone of varying hardness values, which results in a lower hardness value.

On the basis of measurements on the hardness of the cross sections of samples (HV0.1) before and after shot peening, hardness profiles were also determined. Figure 5 shows a hardness profile characteristic for this type of treatment, on which relatively small changes in hardness were observed. Hardness distribution curve indicates the area of enhanced zone extending about $180 \mu \mathrm{m}$ from the surface. Shorter times of shot peening cause the reduction of the hardness but the hardness profiles are similar. Simultaneously with time reduction of shot peening, the depth of the enhanced zone is smaller. The research [18] concludes that sorbitic steels have the least capacity to strengthening by deformation of superficial (15\% strengthening). This is related, among others, with lower susceptibility of fine-grained steel structures (sorbitic steel) to cold plastic deformation. Despite the small ability to strain hardening, sorbitic steels are treated by burnishing.

The surface layer formed in the shot peening process is characterized by a high density of structural defects, such as dislocations. In the surface layer, fragmentation into smaller grains also occurs. From the viewpoint of forming a nitrided layer, defecting the structure, which makes easy diffusion paths, affects the growth of kinetics. The defected surface in shot peening process determines the phase of nucleation of iron (carbo)nitrides zone. Plastic deformation and gradients forming stress have also influenced the process of diffusion of nitrogen atoms to the center of the material and carbon toward the surface.

3.2. The Properties of the Surface Layer after Shot Peening and Nitriding Process. In the next stage, shot-peened samples were treated by nitriding in time $t_{n}=3 \mathrm{~h}(2.2)$. The properties of the layers were determined, as in the previous case, by measuring the surface hardness and the hardness distribution on the cross sections of the samples. In addition, 


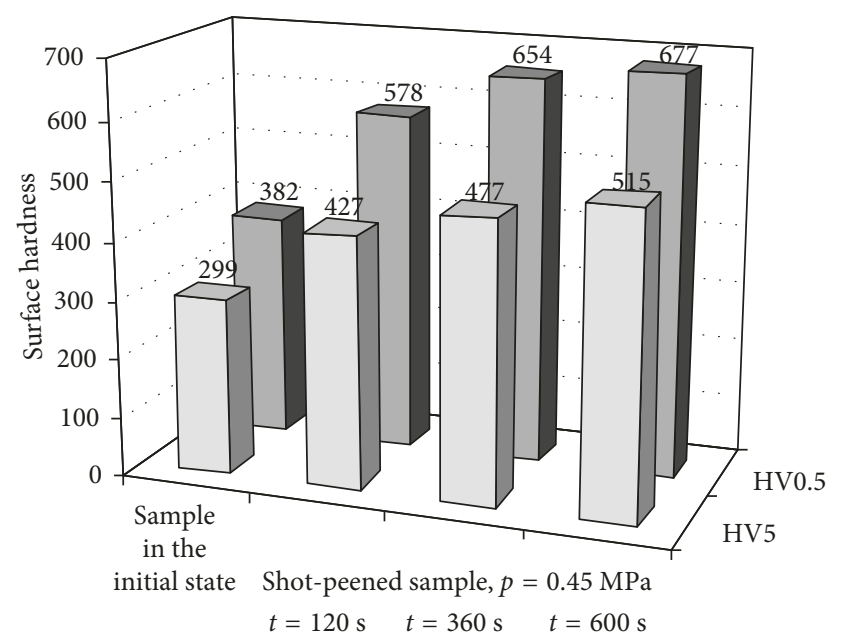

FIGURE 4: The surface hardness of the sample in the initial state and after the shot peening process.

structural studies and phase changes of the nitrided layer by optical microscopy and X-ray diffraction were conducted.

The nitrided layer produced in the process consisted of the external zone of the phase composition $\varepsilon\left(\mathrm{Fe}_{2-3} \mathrm{~N}\right)$ and $\gamma^{\prime}\left(\mathrm{Fe}_{4} \mathrm{~N}\right)$ and the zone of internal nitriding, so-called a diffusion zone. From the analysis of X-ray diffractions presented in Figure 6(a), it comes out that the use of shot peening process as an additional treatment prior to nitriding causes changes in the volume fraction of phases $\varepsilon$ and $\gamma^{\prime}$ in iron (carbo)nitrides zone. For shot peened samples, compared to surface unmodified by plastic treatment samples, one can observe increased $\varepsilon$ phase content in iron (carbo) nitrides zone. The $\varepsilon$ phase content is 67 and $54 \%$, respectively (Figure 6(b)). Consequently, the thickness of iron (carbo) nitride zone grows faster on samples in which the surface layer was modified by shot peening process (Figure 6(c)).

Samples subjected to nitriding process retained variation of hardness caused by various times of shot peening process. These results are illustrated in the bar graph shown in Figure 7. As shown, in the case of samples subjected only to nitriding process, there was an increase in hardness of 402 HV5 (299 HV5 initial state), an increase of $134 \%$. After the shot peening process and then nitriding, the variation in hardness values was, as already mentioned, $216 \mathrm{HV} 5$ after shot peening, and increased to the amount of 248 HV5. Maximal increase of 471 HV5 in hardness was recorded for the sample shot peened at time $t=360 \mathrm{~s}$ and then nitrided, compared with the sample that was only shot peened in which the hardness amounted to 477 HV5 (Figure 4).

Hardness profiles (Figure 8) after the combined process are characterized by a shape similar to that obtained after the shot peening process. If a process is combined, the area of enhanced zone reaches about $250 \mu \mathrm{m}$ from the surface. An increase in hardness in the surface zone of approximately 85 HV0.1 on samples of the combined shot peening and nitriding process was observed. Moreover, hardness profiles are characterized by greater gradient of hardness after combined process compared to the hardness profiles designated after the nitriding process (Figure 8).

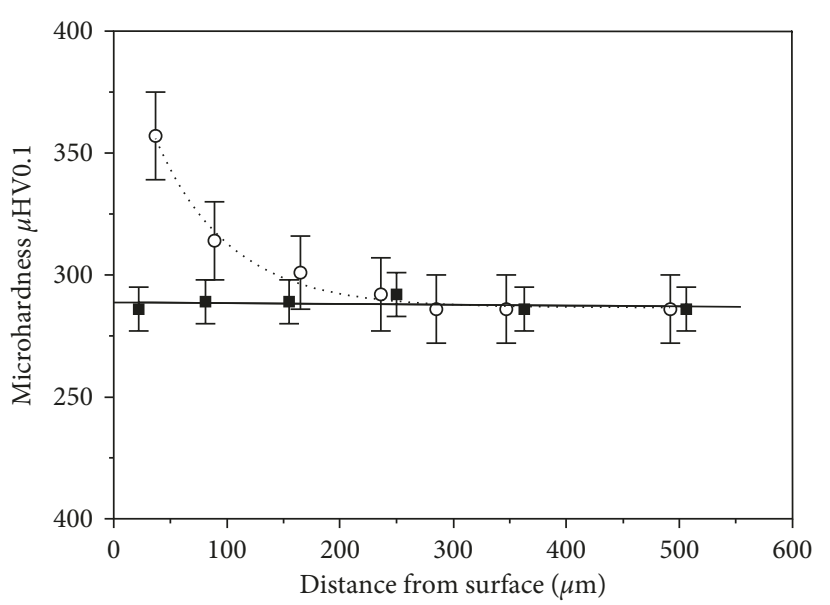

- Sample in the initial state

o Shot-peened sample: $t=360 \mathrm{~s}, p=0.45 \mathrm{MPa}$

FIgURE 5: Distribution of microhardness profiles $\mu \mathrm{HV} 0.1$ in samples before and after shot peening.

\subsection{Adhesion of the Coatings on Modified Substrates}

3.3.1. General Remarks. CrN coatings deposited on 42CrMo4 steel substrates: pure and after thermochemical treatment and/or shot peening are characterized by a uniform thickness throughout the area of its occurrence, good adhesion to the substrate material, and a compact structure without visible delamination. There are no areas of weak adhesion of the coating to the substrate. Basic properties of the coatings summarized in Table 1 are comparable to data presented by other authors [19].

Mechanical properties $(H, E)$ of $\mathrm{CrN}$ coatings (Table 1) are similar to those presented in $[20,21]$. Compressive stress amounted to $1.4 \mathrm{GPa}$ is relatively small compared to $8 \mathrm{GPa}$ [21] or $5 \mathrm{GPa}$ [22]. Similar value of stress $-1.2 \mathrm{GPa}$ is shown in [23].

For single-phase monolayer coatings, macrostress is connected with microstructural damage caused by high-energy ion bombardment during film growth (internal stresses) and mismatch of the thermal expansion coefficients of the coating and the substrate (thermal stress) occurring during cooling from a deposition to room temperature [24]. The value of thermal stress $\sigma_{\text {th }}$ can be calculated using the formula [24]

$$
\sigma_{\mathrm{th}}=\frac{E_{\mathrm{CrN}}}{1-v_{\mathrm{CrN}}} \times\left(\alpha_{\mathrm{CrN}}-\alpha_{\mathrm{sub}}\right) \times\left(T_{\mathrm{dep}}-T_{0}\right),
$$

where $E_{\mathrm{CrN}}$ is the Young modulus of $\mathrm{CrN}$ coating, $v_{\mathrm{CrN}}$ the Poisson ratio of $\mathrm{CrN}$ coating, $\alpha_{\mathrm{CrN}}$ the thermal expansion coefficient of $\mathrm{CrN}, \alpha_{\text {sub }}$ the thermal expansion coefficient of substrate, $T_{\mathrm{dep}}$ the deposition temperature, $T_{0}$ the room temperature.

The thermal stress in $\mathrm{CrN}$ coating-Si substrate system amounts to about $-0.1 \mathrm{GPa}$ and for $\mathrm{CrN}$ coating-steel substrate system about $-0.7 \mathrm{GPa}$. It indicates that the internal compressive stresses for $\mathrm{CrN}$-steel substrate system are higher of about $0.6 \mathrm{GPa}$ and reaches about $2 \mathrm{GPa}$.

On the surface of the coating, macroparticles and craters can be observed (Figure 9). The macroparticles are 


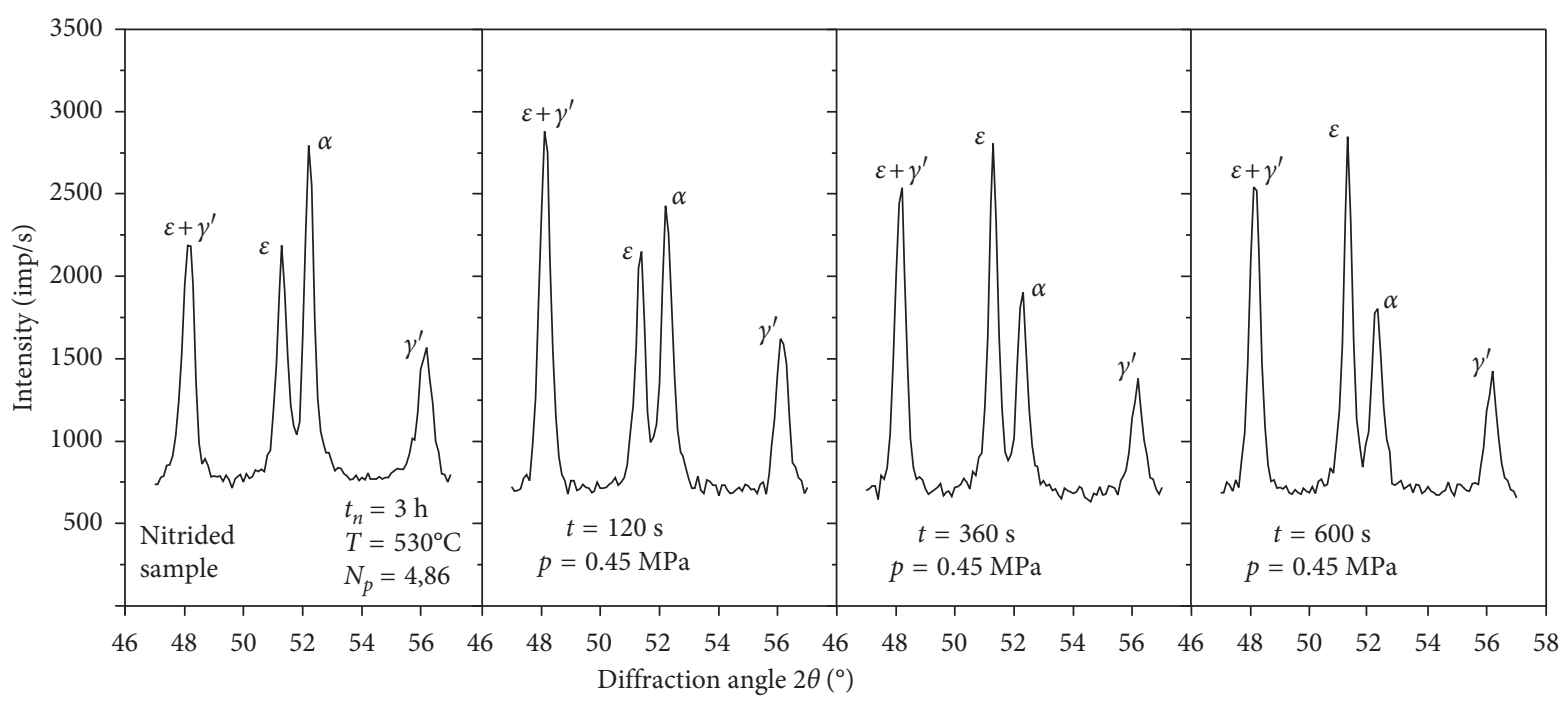

(a)

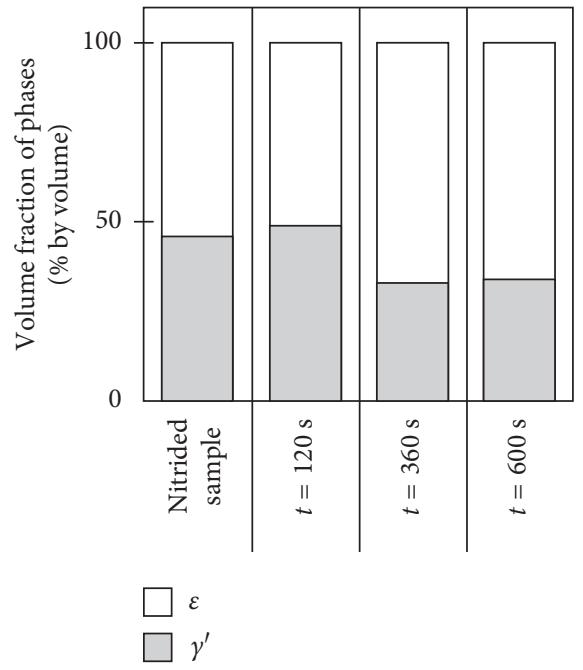

(b)

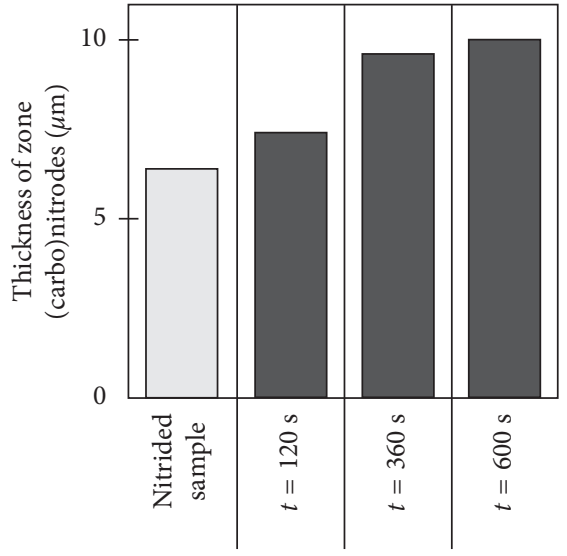

(c)

FIGURE 6: The phase composition of (carbo)nitride zone after nitriding process and after combined shot peening and nitriding process presented by means of X-ray diffraction pattern (a), distribution of volume contents of $\varepsilon$ and $\gamma^{\prime}$ phases in a compound layer (b), and the (carbo)nitride zone thickness (c).

characterized by different sizes, from fractions to some micrometers (Figure 10).

It was found that the macroparticle density decreases with the increase in size above a maximum of around $0.25-0.5 \mu \mathrm{m}$. Only a small number of particles are found below $0.25 \mathrm{~mm}$. The particles with the size of $1 \mu \mathrm{m}$ constitute about $72 \%$ of all particles. The macroparticles are the typical effect of the deposition technique applied, that is, cathodic arc evaporation, and their quality depends on the deposition parameters $[25,26]$.

The composition of the coatings was determined by means of the EDX method. These measurements confirm the presence in the coating, obtained at a nitrogen pressure of $1.8 \mathrm{~Pa}$, of chromium and nitrogen in an amount of about 48 at. \% and 51 at. \%, respectively (Figure 11). This proportion is typical for cubic $\mathrm{CrN}$ phase [27]. Creation of chromium nitride was then confirmed by X-ray studies. It must also be noted that, in all samples, about 1 at. \% of oxygen was recorded.

3.3.2. X-Ray Phase Structure Analysis. Figure 12 shows the diffraction pattern of the obtained CrN coating. All identified diffraction lines, that is, (111), (200), (220), (311), (222), etc., are characteristic in cubic phase of chromium nitride. Diffraction lines from the substrate are not visible due to the identification method-grazing incidence X-ray diffraction.

The observed diffraction lines are shifted about $0.3-0.5^{\circ}$ toward the lower angles with respect to the ICDD data. This is related to the compressive stress in the layer caused by ion 


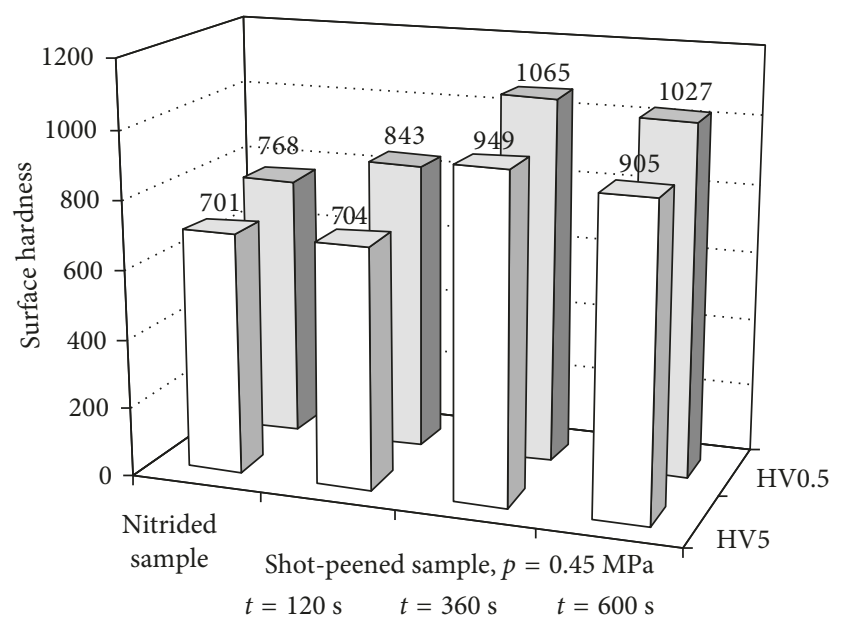

Figure 7: The surface hardness after nitriding process (nitrided sample) and after combined process of shot peening and nitriding.

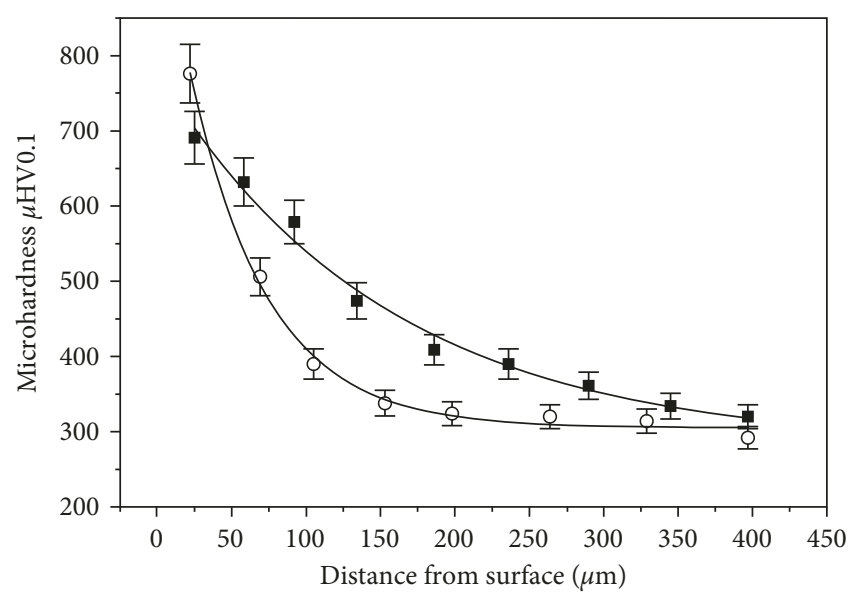

- Nitrided sample

○ Shot-peened sample: $t=360 \mathrm{~s}, p=0.45 \mathrm{MPa}$ and nitrided

Figure 8: Microhardness ( $\mu$ HV0.1) profiles for the samples after nitriding and after combined shot peening and nitriding process.

bombardment during the deposition process. A similar diffraction pattern is shown in [28-31]. The size of the crystallites, calculated using Scherrer's formula, in the coating is about $10 \mathrm{~nm}$.

The diffraction pattern (Figure 12) indicates the difference in the preferred orientation compared to the standard (ICDD 11-0065). It can be noted that the highest intensity is for (111) and then for (200) diffraction line. The intensities of the remaining diffraction lines are close to one another, but more than 10 times less than the intensity of the (111) line. It should be noted that according to the ICDD, the intensity of the diffraction lines is as follows: (111)-80\%, (200)-100\%, (220)-80\%, (311)-60\%, (222)-30\%, (400)-30\%, and (420)$50 \%$. It means that the coating is textured. The values of the texture coefficient, $\mathrm{Tc}$, for the planes are proportional to the number of grains oriented with the corresponding crystallographic plane parallel to the sample surface. The texture coefficient $\mathrm{Tc}(\mathrm{hkl})$ indicates the relative degree of preferred
TABLE 1: The properties of CrN coatings on $42 \mathrm{CrMo} 4$ steel.

\begin{tabular}{lc}
\hline Thickness $(\mu \mathrm{m})$ & $1.8 \pm 0.2$ \\
Hardness, $H(\mathrm{GPa})$ & $23.6 \pm 0.8$ \\
Young's modulus, $E(\mathrm{GPa})$ & $285 \pm 8$ \\
$H / E$ index & $0.082 \pm 0.005$ \\
Stress, $\sigma(\mathrm{GPa})$ & $-1.4 \pm 0.2$ \\
\hline
\end{tabular}

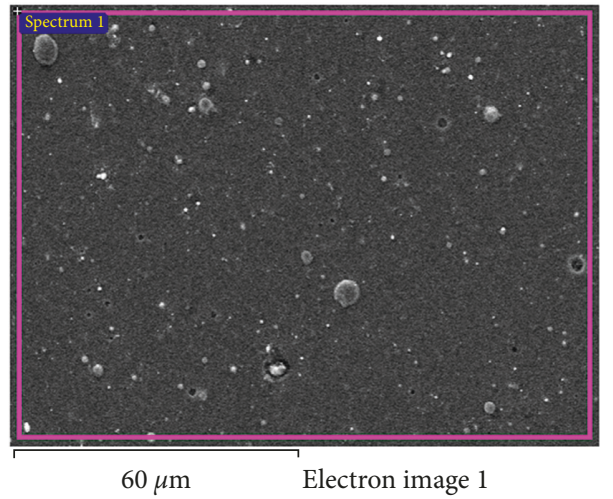

FIGURE 9: SEM image of CrN coating surface in EDS analysis.

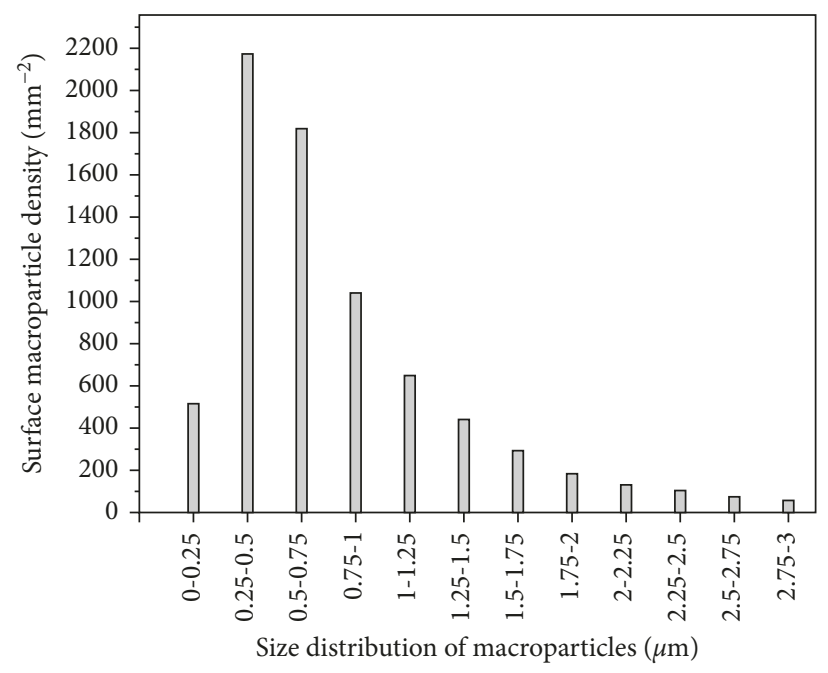

FIgURE 10: Size distribution and macroparticle density of the CrN coating on $42 \mathrm{CrMo} 4$ steel substrate.

orientation among crystal planes. It was calculated using the following equation [32]

$$
\mathrm{Tc}(\mathrm{hkl})=\frac{I(\mathrm{hkl}) / I_{\mathrm{o}}(\mathrm{hkl})}{1 / n \cdot \sum_{1}^{n} I(\mathrm{hkl}) / I_{\mathrm{o}}(\mathrm{hkl})},
$$

where $I(\mathrm{hkl})$ is the diffraction line intensity from the (hkl) plane for the textured sample, $I_{\mathrm{o}}(\mathrm{hkl})$ the respective intensity corresponding to the bulk CrN data from JCPDS File number 11-0065, and $n$ the number of diffraction lines analyzed.

The $\operatorname{Tc}(\mathrm{hkl})$ data are gathered in Table 2. The value of the Tc is proportional to the number of preferentially oriented (hkl) planes. $\mathrm{Tc}(\mathrm{hkl})$ close to unity indicates a randomly distributed powder sample, and $\operatorname{Tc}(\mathrm{hkl})>1$ 


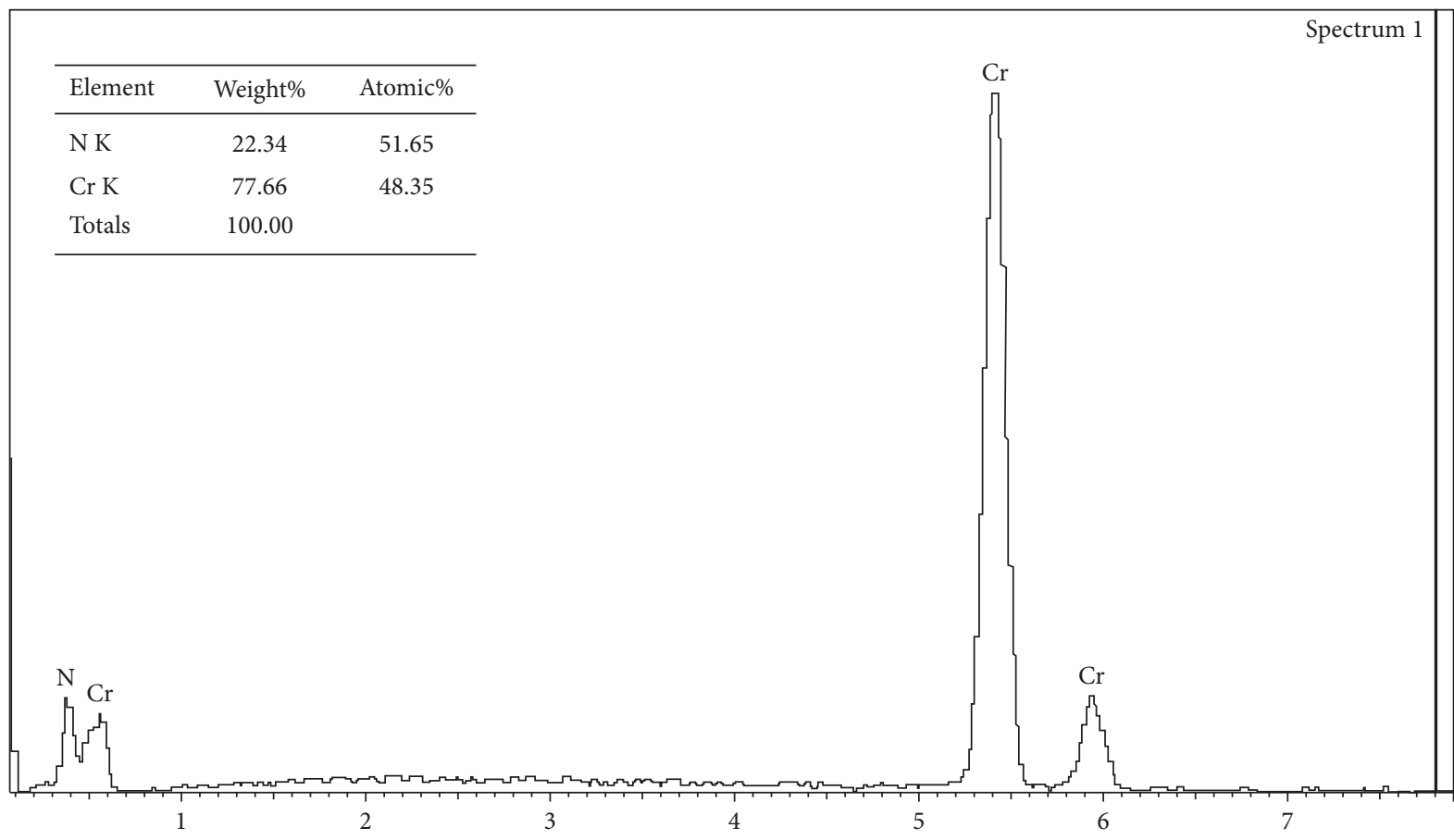

Full scale 1804 cts cursor: 7.805 (8 cts)

FIGURE 11: The EDS analysis of CrN coating from area shown in Figure 9.

indicates preferential orientation. High preferred orientation is attributed to many grains in this orientation.

3.3.3. Adhesion of the Coatings. Of many methods for determining the adhesion, one of the simplest and widely used is a scratch test. This method is characterized by a relatively short measurement time and high repeatability of easily interpretable results, and it simulates the load (stress) occurring during the use of the product with the coating. Applying a linearly increasing normal force to the coating-substrate system tested generates a stress, which may have both a tensile and compressive character. These stresses commonly affect the stresses arising in the coating occurring as a result of difference in thermal expansion coefficients of the substrate material and the coating. After exceeding the critical value of stress, the coating is removed-this corresponds to the critical load Lc. Such damage is an adhesive. Damage to the cohesion of the layer-substrate system occurring outside the surface of the layer-substrate contact shows good adhesion of the coating to the substrate. The sliding of a loaded diamond indenter on the coating is accompanied by plastic deformation of the substrate and pressing the indenter into the coating. There is also a shear force acting on the indentation-coating boundary.

Damage to the coating can take several forms such as cohesive, adhesive, or conformal crack, coating delamination from the substrate, chipping, flaking off, etc. [33]. The variety of possible defects of the coating in the scratch test makes consistent interpretation of results difficult.

Figure 13 shows the results obtained from the scratch tests carried out on $\mathrm{CrN}$ coatings deposited on the substrate

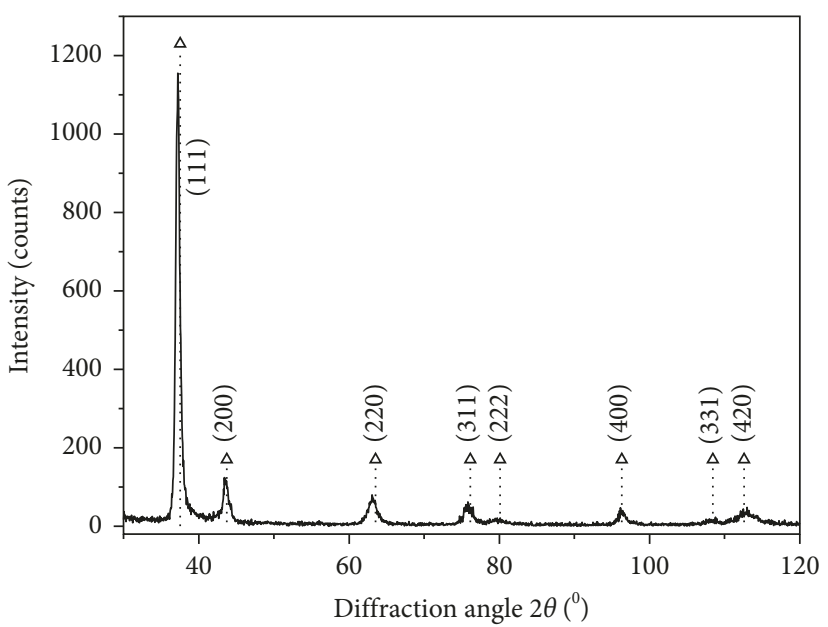

Figure 12: Diffraction pattern of the $\mathrm{CrN}$ coating on the steel 42CrMo4 substrate.

TABle 2: The $\mathrm{Tc}(\mathrm{hkl})$ texture coefficient for CrN coating.

\begin{tabular}{lllllllll}
\hline (hkl) plane (111) (200) (220) (311) & (222) (400) (331) & (420)
\end{tabular}

\begin{tabular}{lllllllll}
$\mathrm{Tc}(\mathrm{hkl})$ & 5.76 & 0.44 & 0.35 & 0.36 & 0.13 & 0.56 & 0.14 & 0.26 \\
\hline
\end{tabular}

without shot peening and on the modified shot peening substrates. All samples were characterized by the critical force $\mathrm{Lc}_{2}$ in the range of $35-40 \mathrm{~N}$, comparable to the critical force of the coating on the substrate in the initial state. As shown in Figures 1(b)-1(d), after shot peening, the surface layer was not compact, which resulted in a high surface roughness (Figure 2). In this case, prior to deposition of the 


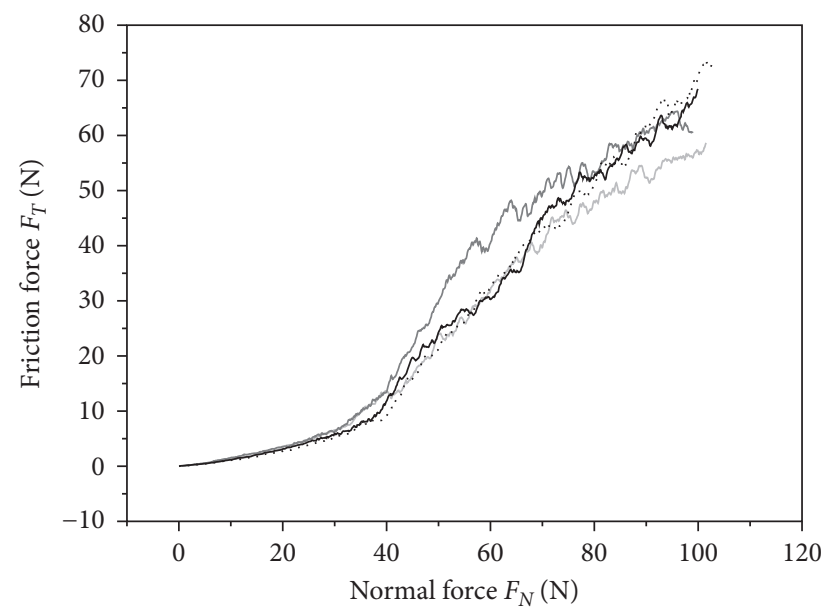

Shot-peened sample, $p=0.45 \mathrm{MPa}$

$$
\begin{aligned}
& -t=120 \mathrm{~s} \quad-t=600 \mathrm{~s} \\
& \text { … } t=360 \mathrm{~s} \quad \text { - Sample in initial state }
\end{aligned}
$$

Figure 13: The friction force for a progressive load scratch test on $\mathrm{CrN}$ coating deposited on substrate without shot peening and after shot peening with different treatment parameters plotted versus the applied load.

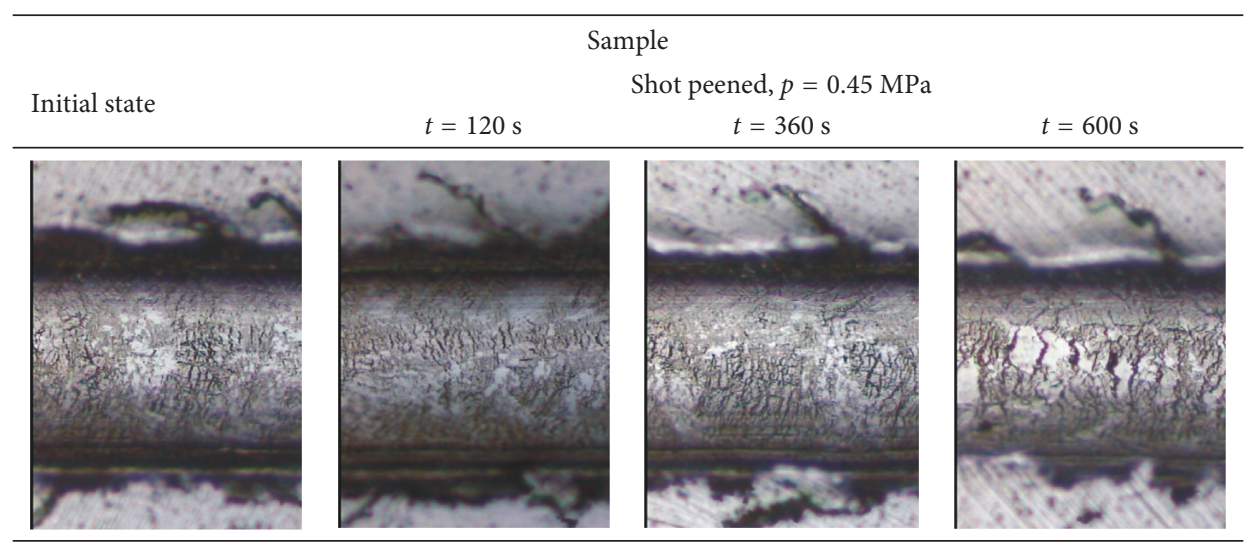

Figure 14: A fragment of the scratches corresponding to the load from the range of $37-42 \mathrm{~N}$ for CrN coatings deposited on shot peening-treated substrates and the untreated substrate.

coating, surface grinding was performed in order to improve the quality of the surface and reduce the roughness. Hardness measurements performed showed that the hardness of the substrate was reduced by about $50 \mathrm{HV} 0.5$. Despite the increase in the hardness of the shot peening processed substrates, there was no difference in the critical load Lc of the samples. Detailed analysis indicates even a slight decrease in the critical load for the sample with the longest time of shot peening, $600 \mathrm{~s}$. This may result from greater number of defects in the structure, increasing the surface hardness.

Comparison of coating damage in scratch test is rather difficult because of the different properties of the coatingsubstrate system tested. Film thickness, hardness of the substrate, and the stresses arising at the diamond indentercoating interface are the main factors that have an impact on the critical force Lc [2]. Therefore, the measurements were performed for systems in which the coatings show the uniform thickness of $(1.8 \pm 0.2) \mu \mathrm{m}$. The strong effect on the adhesion of the coating to the substrate, determining the critical load Lc, is adequate for substrate surface preparation. Particularly important is the ionic cleaning, conducted directly before the coating process, which removes the surface oxide layer and the weakly bonded impurities. The procedure was used for the deposition of the coatings studied.

Figure 14 shows the photos of scratches made with a load of $37-42 \mathrm{~N}$ and the damages of the coatings. It was found that in all the coatings, there is brittle fracture, particularly evident in the bottom and the edge of the scratch. In the case of a coating deposited on the substrate after shot peening treatment $(600 \mathrm{~s})$, it can be observed as definitely getting the most spallings in the track of friction. 


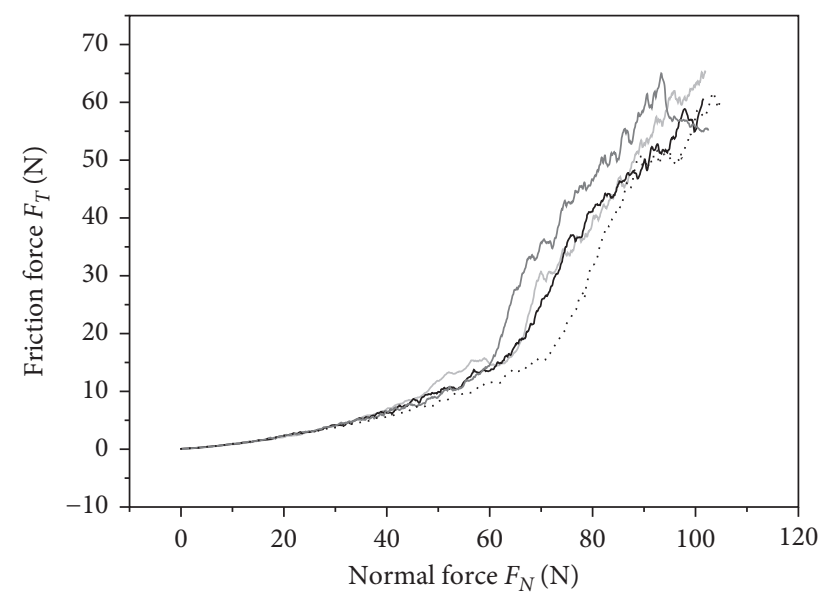

$$
\begin{aligned}
& \text { Shot-peened sample }(p=0.45 \mathrm{MPa}) \text { and nitrided } t_{n}=3 \mathrm{~h} \\
& t=120 \mathrm{~s} \\
& -t=360 \mathrm{~s} \\
& -\ldots . .
\end{aligned}
$$

Figure 15: The results of the scratch test of the CrN coating on nitrided substrate and substrates subjected by combined shot peening and nitriding processes, nitriding time $t_{n}=3 \mathrm{~h}$.

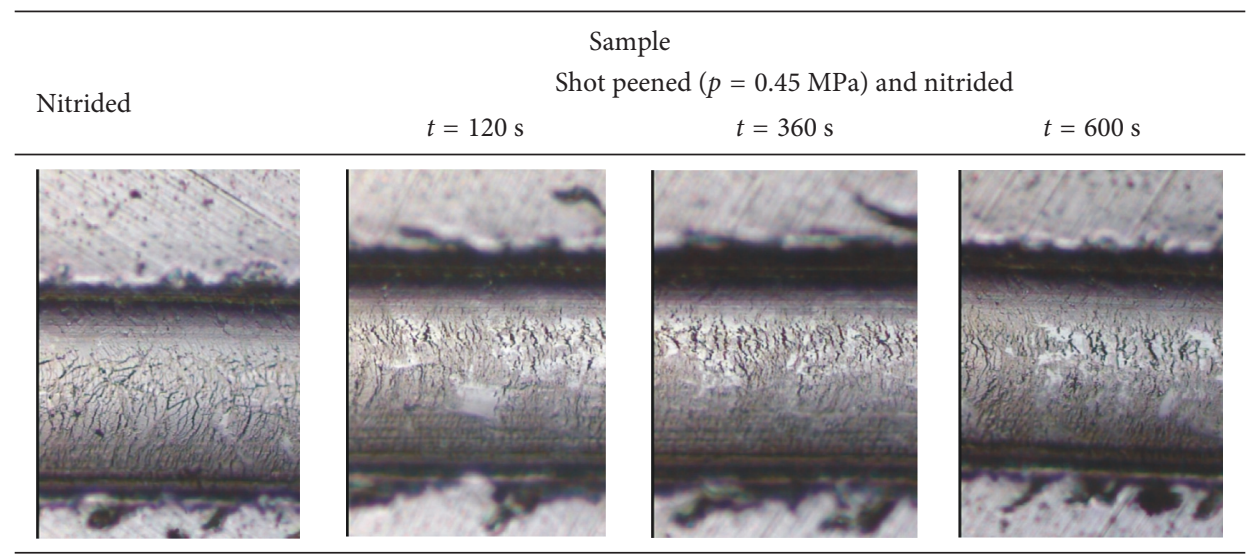

Figure 16: A fragment of the scratches corresponding to the load in the range of $60-65 \mathrm{~N}$ for CrN coatings deposited on nitrided substrate and combined shot peening and nitriding process-treated substrates.

Substrates after successive shot peening and nitriding show much higher hardness (about 50\%) than after the shot peening process. This certainly contributed to the observed (Figure 15) increase in the critical load, that is $60-67 \mathrm{~N}$, and for a substrate only nitrided, even $74 \mathrm{~N}$. The slightly lower value for the substrate with the largest shot peening time is probably connected with the lower surface hardness (Figure 7). The nature of these changes, that is, a relationship of substrate hardness and critical force was previously presented by Ichimura and Rodrigo [1]. Slightly lower critical load for the CrN coating deposited on the substrate subjected to shot peening and nitriding treatment compared to the nitrided substrate results from the nature of the surface layer after these treatments. After shot peening, there is a large development of the substrate surface (higher roughness, Figure 2), and nitriding impairs the condition. The parts of the machined surface are weakly associated with the core result in lower adhesion of the coating to the substrate.

The photos of the scratches performed for loads in the range of 60-65 N (Figure 16), at the same magnification, show the slightly different nature of the coating damage than those shown in Figure 16. CrN coating cracks are smaller due to the cohesive coating cracking and/or bending of the coating in the direction of the motion of a diamond indenter.

The flaking off of the coating which may lead to partial exposure of the substrate or even force in coating into the substrate can be seen. Gas nitriding of the substrate (first stage of treatment causes an increase in its hardness) limits the fragmentation of coating by the restriction of the substrate plastic deformation. The total detachment of coating from the substrate was not observed. 

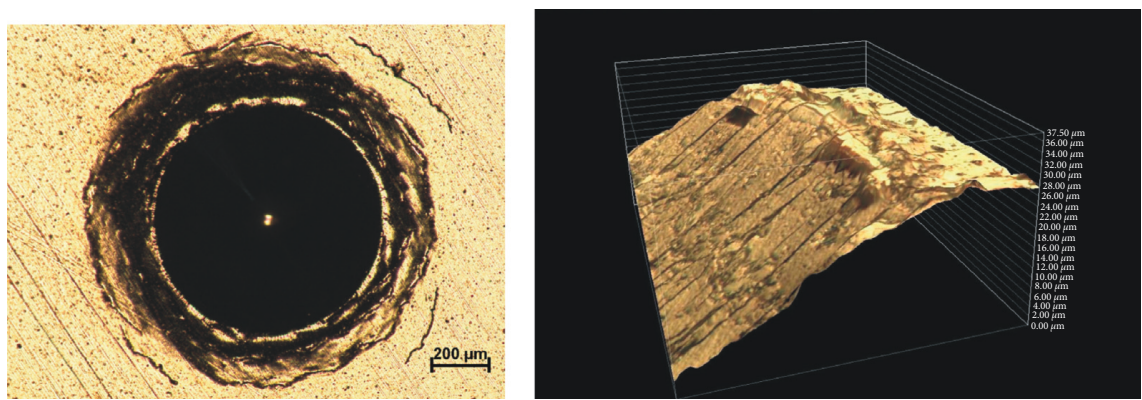

(a)
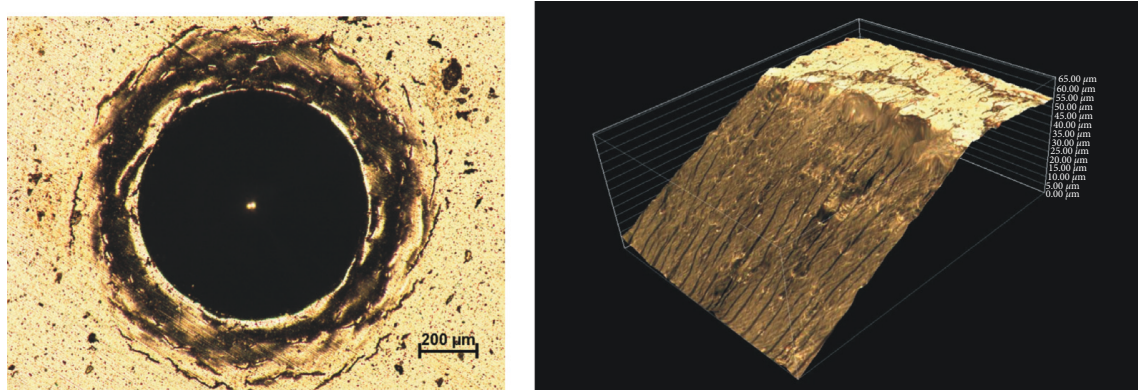

(b)
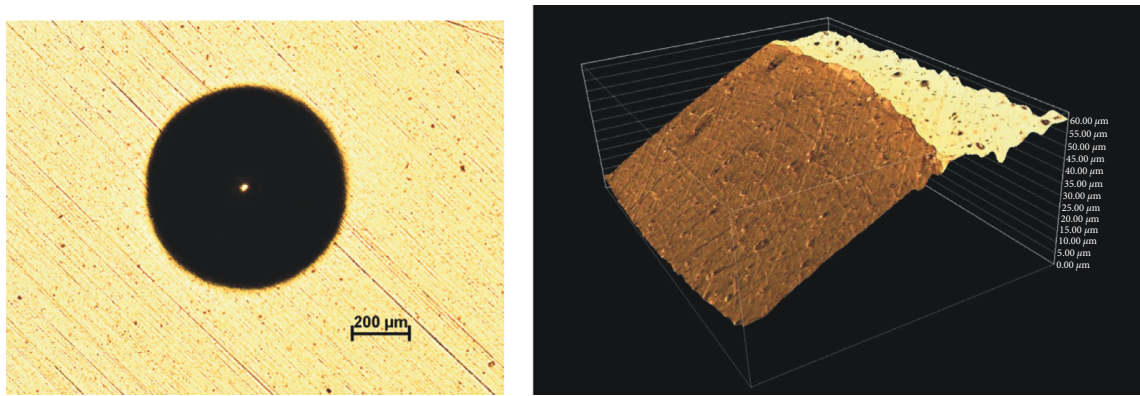

(c)
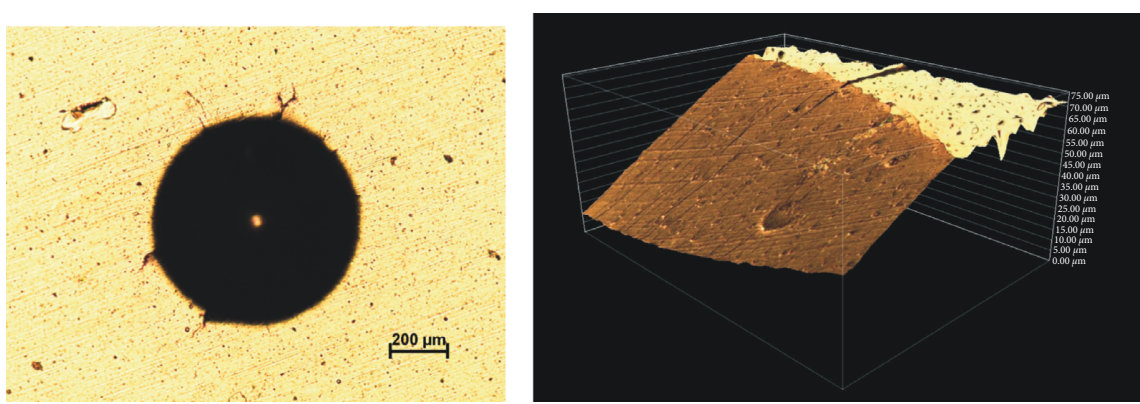

(d)

Figure 17: Failure modes after Daimler-Benz test (left column) and 3D visualization of the selected indent morphology (right column) for CrN coatings deposited on (a) initial substrates, (b) shot-peened substrate ( $t=600 \mathrm{~s}, p=0.45 \mathrm{MPa})$, (c) nitrided substrate $\left(t_{n}=3 \mathrm{~h}\right)$, and (d) shot-peened $(t=600 \mathrm{~s}, \mathrm{p}=0.45 \mathrm{MPa})$ and nitrided substrate $\left(t_{n}=3 \mathrm{~h}\right)$.

Rockwell diamond indenter movement may cause plastic deformation of the coating and the substrate. Despite this, there is no delamination of the coatings. Similar observations in the complex of nitriding and PVD thin coating deposition processes were reported by Chang et al. [34]. This indicates the excellent toughness and adhesion of coatings.

An easy-to-use test for the evaluation of hard coating adhesion to the substrate is the Daimler-Benz test. The examination shall cover an area both inside and outside the indentation in terms of the type of coating damage: radial cracks, angular intersecting cracks, coating delamination, or the combination of its defects. In the hard coatings with good coherence arise only small radial cracks if any. These coatings with good adhesion do not exhibit delamination neither in indentation nor in its direct surrounding. The test results for $\mathrm{CrN}$ coatings 
deposited on different substrates without any treatment, after the shot peening treatment, nitriding, and the combination of the nitriding and shot peening treatments are shown in Figures 17(a)-17(d), respectively. For a proper evaluation the images of coating-substrate systems are presented in the same magnification. One can see the different "responses" of the substrate-coating system on the load. In Figures 17(a) and 17(b), there is a so-called pile up of substrate materials on the border of the coatingindentation resulting in peripheral cracks. These effects can be seen in the accompanying $3 \mathrm{D}$ images, which also reveal a number of radial cracks and the chipping of the coating inside the indentation. In Figure 17(c) illustrating the test result for a coating deposited onto the nitrided only substrate, previously described damages to the coating are not present. 3D image of the sample shows a smooth surface within the indentation. $\mathrm{CrN}$ coating deposited onto multistage- (shot peening and nitriding-) treated substrate (Figure 17(d)) shows a few radial cracks which are also revealed in the $3 \mathrm{D}$ image.

The test results confirm a very good adhesion of the coating to the nitrided substrates. The substrate subjected also to shot peening treatment, despite higher hardness, shows a greater amount of damage. Thus, a process of nitriding in the multistage substrate treatment is crucial to improve the adhesion of the coating to the substrate. The test results confirm those obtained with the scratch test.

\section{Conclusions}

The use of modern technology significantly improves the tool materials. These modified substrate-coating systems provide a significant increase in service performance, both for dry cutting and at high cutting speeds.

In this study, the substrates were modified by machining (shot peening), by thermochemical treatment (nitriding), and by the combination of these two processes. A thin hard $\mathrm{CrN}$ coating was deposited on different substrates modified. To assess the adhesion, the scratch test and the DaimlerBenz test were used. The results are as follows:

(a) In the shot peening process, depending on the process parameters, the hardness of the material increases by about $50 \%$. With increasing the shot peening time, the hardness also increases. Simultaneously, the surface roughness parameters $R_{a}$ also significantly increases (about 20 times).

(b) The substrates subjected to a combined treatment consisting of the shot peening and nitriding show a hardness of about $50 \%$ higher than after the shot peening and about $40 \%$ higher than after the nitriding. The highest hardness was obtained for the following parameters of shot peening: pressure of $0.45 \mathrm{MPa}$ and time of $360 \mathrm{~s}$. Elongation in shot peening time resulted in a hardness decrease of about 50 HV0.5.

(c) Surface modification processes used increase adhesion of the coating, which is due to the increase of its hardness.

\section{Conflicts of Interest}

The authors declare that there are no conflicts of interest.

\section{References}

[1] H. Ichimura and A. Rodrigo, "The correlation of scratch adhesion with composite hardness for TiN coatings," Surface and Coatings Technology, vol. 126, no. 2-3, pp. 152-158, 2000.

[2] S. J. Bull, D. G Bhat, and M. H. Staia, "Properties and performance of commercial TiCN coatings. Part 2: tribological performance," Surface and Coatings Technology, vol. 163-164, pp. 507-514, 2003.

[3] A. Nakonieczny, "Forecasting and testing of mechanical properties of surface layers of metals (in Polish)," Surface Engineering, vol. 6, no. 1, pp. 3-16, 2001.

[4] T. Burakowski and T. Wierzchoń, Surface Engineering of Metals, CRC Press, Boca Raton, FL, USA, 1999.

[5] A. Nakonieczny, The Performance Features of Metal Products Heat-Treated (in Polish), Institute of Precision Mechanics, Warsaw, Poland, 1999.

[6] L. Chekour, C. Nouveau, A. Chala, and M. A. Djouadi, "Duplex treatment of 32CrMoV13 steel by ionic nitriding and triode sputtering: application to wood machining," Wear, vol. 255, no. 7-12, pp. 1438-1443, 2003.

[7] R. Hoy, J.-D. Kamminga, and G. C. A. M. Janssen, "Scratch resistance of $\mathrm{CrN}$ coatings on nitrided steel," Surface and Coatings Technology, vol. 200, no. 12-13, pp. 3856-3860, 2006.

[8] H. Paschke, M. Weber, P. Kaestner, and G. Braeuer, "Influence of different plasma nitriding treatments on the wear and crack behavior of forging tools evaluated by Rockvell indentation and scratch test," Surface and Coatings Technology, vol. 205, no. 5, pp. 1465-1469, 2010.

[9] Ö. Alpaslan, E. Atar, and H. Çimenoğlu, "Tribological behaviour of duplex treated AISI 4140 steel," JESTECH, vol. 15, no. 1, pp. 39-43, 2012.

[10] D. Liu, X. Zhu, B. Tang, and J. He, "Fretting fatigue improvement of Ti6Al14V by coating and shot peening," Journal of Materials Science \& Technology, vol. 21, pp. 246-250, 2005.

[11] Y. Fu, N. L. Loh, A. W. Batchelor et al., "Improvement in fretting wear and fatigue resistance of Ti-6Al-4V by application of several surface treatments and coatings," Surface and Coatings Technology, vol. 106, no. 2-3, pp. 193-197, 1998.

[12] J. Walkowicz, J. Smolik, and K. Miernik, "Investigation of the influence of ion etching parameters on the structure of nitrided case in hot working steel," Surface and Coatings Technology, vol. 116-119, pp. 361-366, 1999.

[13] S. M. Aouadi, D. M. Schultze, S. L. Rohde, K. C. Wong, and K. A. R. Mitchell, "Growth and characterization of Cr2N/CrN multilayer coatings," Surface and Coatings Technology, vol. 140, no. 3, pp. 269-277, 2001.

[14] S. C. Lee, W. Y. Ho, and F. D. Lai, "Effect of substrate surface roughness on the characteristics of CrN hard films," Materials Chemistry and Physics, vol. 43, no. 3, pp. 266-273, 1996.

[15] B. D. Cullity, Elements of X-ray Diffraction, Addison-Wesley Publishing Company Inc., London, UK, 2nd edition, 1978.

[16] J. Ratajski, "Relation between phase composition of compound zone and growth kinetics of diffusion zone during nitriding of steel," Surface \& Coatings Technology, vol. 203, no. 16, pp. 2300-2306, 2009.

[17] G. G. Stoney, "The tension of metallic films deposited by electrolysis," Proceedings of the Royal Society of London. Series A, Containing Papers of a Mathematical and Physical Character, vol. 82, no. 507, pp. 172-175, 1909. 
[18] W. Przybylski, The Processing Technology of Burnishing (in Polish), Publisher of Scientific and Technical, Warsaw, Poland, 1987.

[19] C. Nouveau, M. A. Djouadi, and C. Decès-Petit, "The influence of deposition parameters on the wear resistance of $\mathrm{Cr}_{x} \mathrm{~N}_{y}$ magnetron sputtering coatings in routing of oriented strand board," Surface and Coatings Technology, vol. 174-175, pp. $455-460,2003$.

[20] B. Warcholinski and A. Gilewicz, "Effect of substrate bias voltage on the properties of $\mathrm{CrCN}$ and $\mathrm{CrN}$ coatings deposited by cathodic arc evaporation," Vacuum, vol. 90, pp. 145-150, 2013.

[21] M. Odén, C. Ericsson, G. Hakansson, and H. Ljungcrantz, "Microstructure and mechanical behavior of arc-evaporated Cr-N coatings," Surface and Coatings Technology, vol. 114, no. 1 , pp. 39-51, 1999.

[22] X. S. Wan, S. S. Zhao, Y. Yang, J. Gong, and C. Sun, "Effects of nitrogen pressure and pulse bias voltage on the properties of $\mathrm{Cr}-\mathrm{N}$ coatings deposited by arc ion plating," Surface and Coatings Technology, vol. 204, no. 11, pp. 1800-1810, 2010.

[23] A. Gilewicz, B. Warcholinski, P. Myslinski, and W. Szymański, "Anti-wear multilayer coatings based on chromium nitride for wood machining tools," Wear, vol. 270, no. 1-2, pp. 32-38, 2010.

[24] M. Odén, J. Almer, and G. Håkansson, “The effects of bias voltage and annealing on the microstructure and residual stress of arc-evaporated Cr-N coatings," Surface and Coatings Technology, vol. 120-121, pp. 272-276, 1999.

[25] V. D. Ovcharenko, A. S. Kuprin, G. N. Tolmachova et al., "Deposition of chromium nitride coatings using vacuum arc plasma in increased negative substrate bias voltage," Vacuum, vol. 117, pp. 27-34, 2015.

[26] V. D. Ovcharenko, A. S. Kuprin, G. N. Tolmachova et al., "Deposition of chromium nitride coatings from vacuum arc plasma in increased nitrogen pressure," Problems of Atomic Science and Technology, vol. 6, no. 20, pp. 204-207, 2014.

[27] J. W. Seok, N. M. Jadeed, and R. Y. Lin, "Sputter deposited nanocrystalline $\mathrm{Cr}$ and $\mathrm{CrN}$ coatings on steels," Surface and Coatings Technology, vol. 138, no. 1, pp. 14-22, 2001.

[28] J. Kusinski, M. Rozmus, and J. Bujak, "Investigation of the life-time of drills covered with the anti-wear $\mathrm{Cr}(\mathrm{C}, \mathrm{N})$ complex coatings, deposited by means of Arc-PVD technique," Journal of Achievements in Materials and Manufacturing Engineering, vol. 33, no. 1, pp. 86-93, 2009.

[29] J. Esteve, J. Romero, M. Gómez, and A. Lousa, "Cathode chromium carbide coatings for molding die applications," Surface and Coatings Technology, vol. 188-189, pp. 506-510, 2004.

[30] M. Čekada, P. Panjan, M. Maček, and P. Šmid, "Comparison of structural and chemical properties of Cr-based hard coatings," Surface and Coatings Technology, vol. 151-152, pp. 31-35, 2002.

[31] J. Romero, E. Martinez, J. Esteve, and A. Lousa, "Nanometric chromium nitride/chromium carbide multilayers by r.f. magnetron sputtering," Surface and Coatings Technology, vol. 180-181, pp. 335-340, 2004.

[32] C. S. Barret and T. B. Massalski, Structure of Metals, Pergamon Press, Oxford, UK, 1980.

[33] S. J. Bull, "Failure mode maps in the thin film scratch adhesion test," Tribology International, vol. 30, no. 7, pp. 491-498, 1997.

[34] Y. Y. Chang, D. Y. Wang, and C. Y. Hung, "Structural and mechanical properties of nanolayered TiAlN/CrN coatings synthesized by a cathodic arc deposition process," Surface and Coatings Technology, vol. 200, no. 5-6, pp. 1702-1708, 2005. 

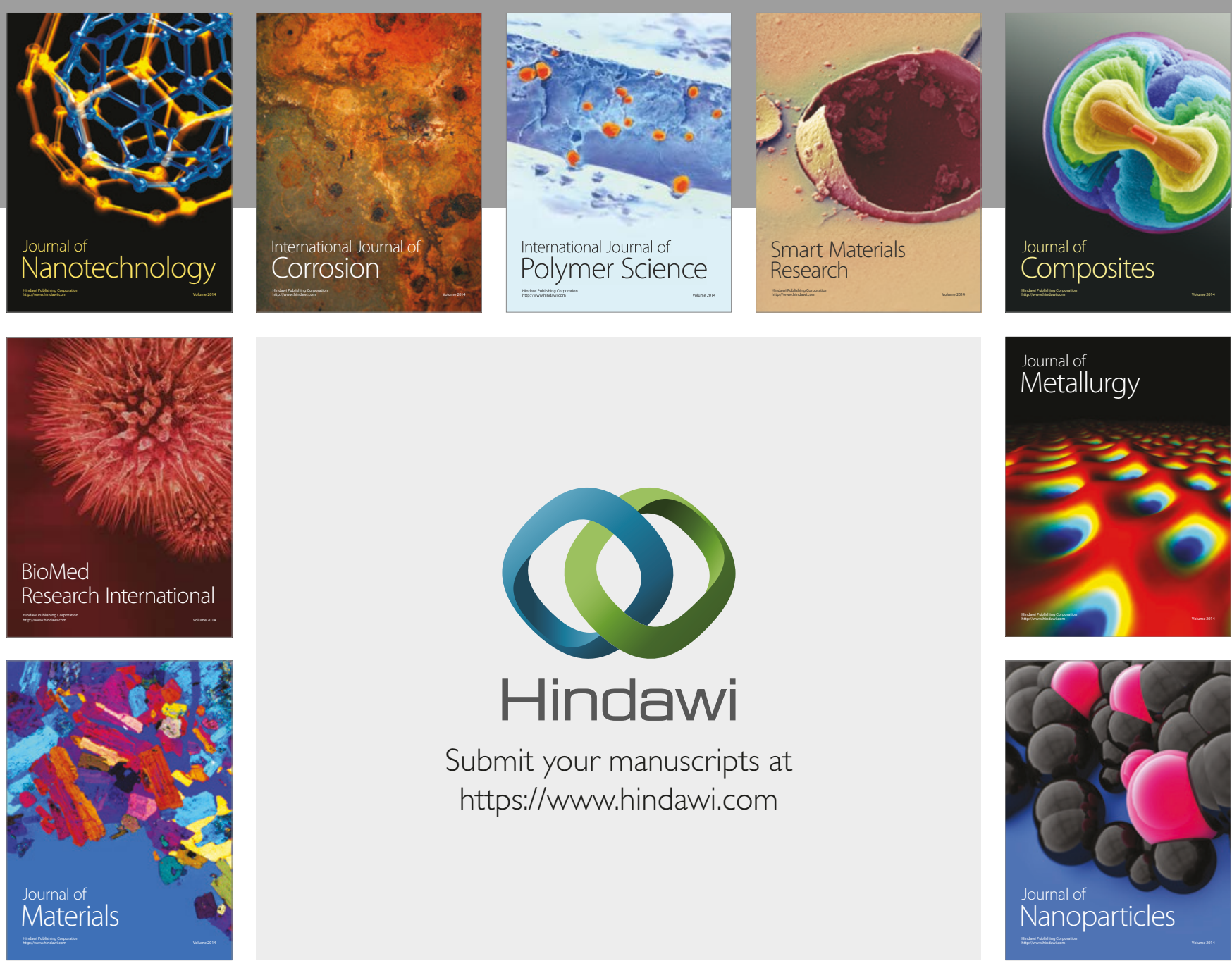

\section{Hindawi}

Submit your manuscripts at

https://www.hindawi.com
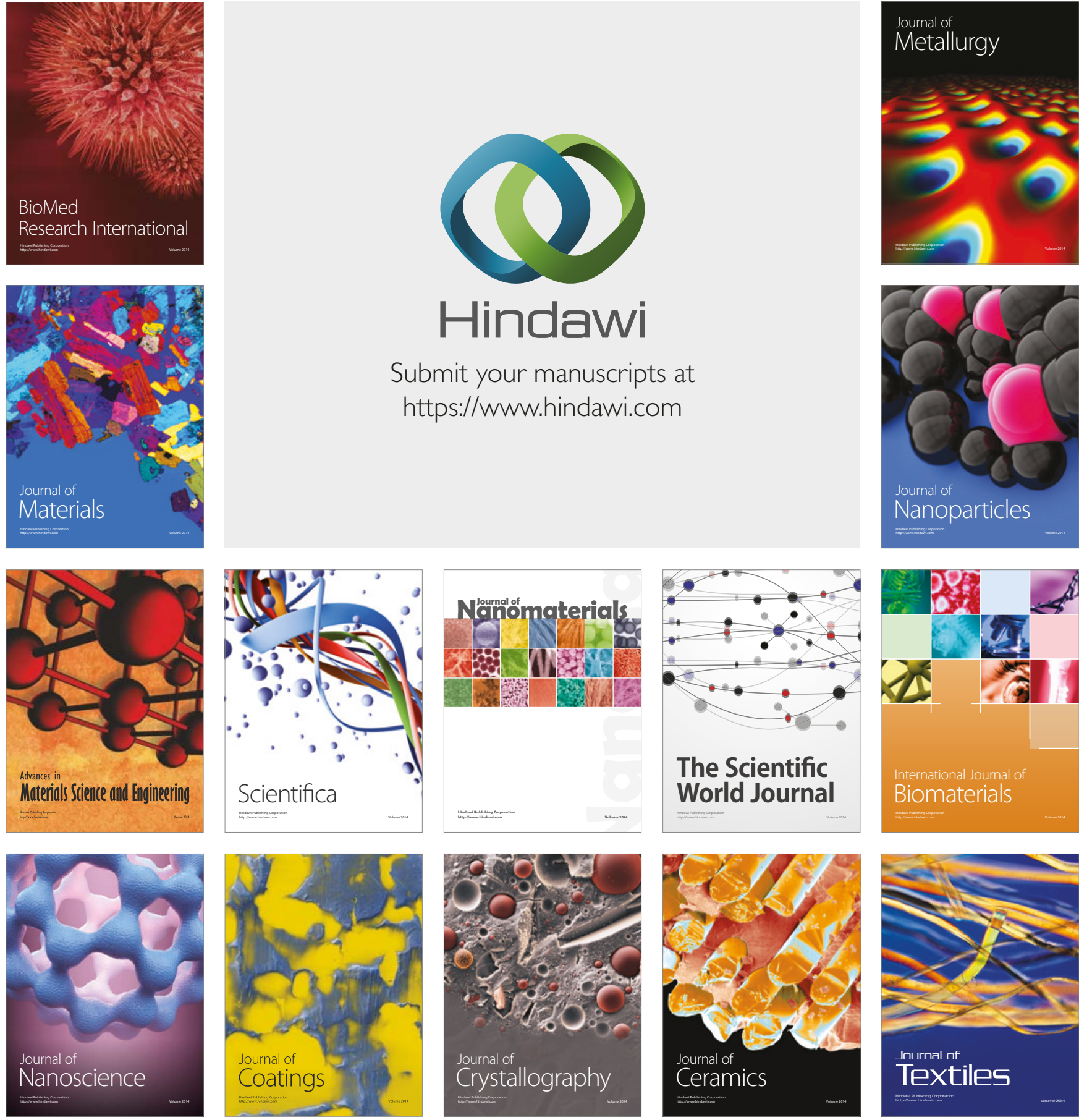

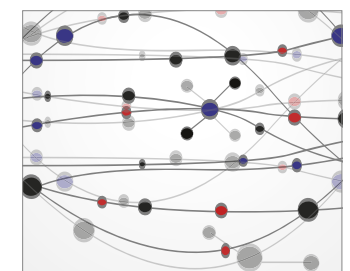

The Scientific World Journal
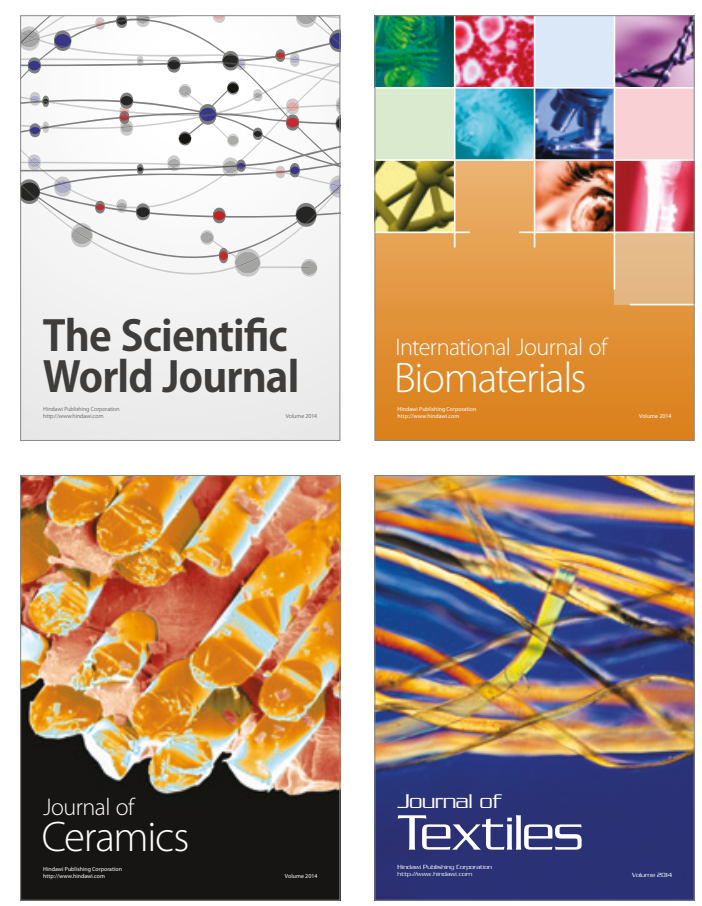